\title{
ARTIGOS
}

\section{DESAFIOS DO ENSINO MÉDIO \\ NO BRASIL: INICIATIVAS DAS \\ SECRETARIAS DE EDUCAÇÃO}

\author{
GISELA LOBO B. P. TARTUCE' \\ GABRIELA MIRANDA MORICONI" \\ CLAUDIA L. F. DAVISIII \\ MARINA M. R. NUNESIV
}

\section{RESUMO}

Este artigo traz parte dos resultados de uma pesquisa que, desenvolvida durante 2014 e 2015, procurou construir um diagnóstico sobre políticas educacionais para o ensino médio - especialmente as curriculares -, valendo-se, para tanto, de informações pesquisadas junto aos estados brasileiros e ao Distrito Federal, os maiores responsáveis pela oferta desse nível de ensino. Os dados foram coletados por meio de: documentos e disposições legais vigentes; questionários às equipes responsáveis pelo ensino médio nas secretarias de educação de todos os estados do país; e entrevistas qualitativas realizadas junto a uma amostra de dez secretarias dentre as 27. Neste texto especificamente, o objetivo é apresentar e analisar algumas iniciativas que os entes federados têm desenvolvido para atrair e manter os jovens nesse nível de ensino.

ENSINO MÉDIO • POLÍTICAS EDUCACIONAIS • CURRÍCULOS • JUVENTUDE

\section{CHALLENGES OF HIGH SCHOOL IN BRAZIL: INITIATIVES OF EDUCATION SECRETARIATS}

\section{ABSTRACT}

This article presents part of the results of a study conducted in 2014 and 2015. It sought to build a diagnosis of educational policies for secondary school, especially

Fundação Carlos Chagas (FCC), São Paulo (SP), Brasil; gtartuce@fcc.org.br

FCC, São Paulo (SP), Brasil gmoriconi@fcc.org.br Universidade Católica de São Paulo (PUC-SP) São Paulo (SP), Brasil: cdavis@fcc.org.br

IV

FCC e Colégio Santa Cruz, São Paulo (SP), Brasil mnunes@fcc.org.br regarding the curricula, using information collected from the Brazilian states and the Federal District, those with the greatest responsibility for the education offered at this level. The data were collected through: current legal provisions and documents; questionnaires sent to the teams responsible for this level of education at the secretariats of education in all states in the country; and, qualitative interviews conducted with a sample of ten, of the 27, Secretariats of Education in the country. This text aims specifically at presenting and analyzing some initiatives that the federated entities have developed to attract and retain young people in this level of education. 


\section{DÉFIS DE L'ENSEIGNEMENT MOYEN AU BRÉSIL: INITIATIVES DES SECRÉTARIATS DE L'ÉDUCATION \\ RÉSUMÉ}

Cet article reprend une partie des résultats d'une recherche menée entre 2014 et 2015 visant à élaborer un diagnostic à propos des politiques éducatives pour l'enseignement secondaire et, plus particulièrement, des programmes d'études Les informations apportées proviennent des états brésiliens et du District Fédéral, les plus grands responsables de l'offre de ce niveau d'enseignement. Les données recueillies sont issues de documents et de dispositions légales, de questionnaires auprès des équipes ayant à charge ce niveau d'enseignement au sein des secrétariats de l'éducation de tous les états du pays, ainsi que d'entretiens de type qualitatif réalisés à partir d'un échantillon de dix secrétariats parmi les 27 existants. L'objectif spécifique de ce texte est de présenter et d'analyser certaines initiatives que les collectivités fédérées ont développées pour attirer et maintenir les jeunes dans ce niveau d'enseignement.

ENSEIGNEMENT SECONDAIRE • POLITIQUES ÉDUCATIVES •

CURRICULUM・JEUNESSE

\section{DESAFÍOS DE LA ENSEÑANZA MEDIA EN BRASIL: INICIATIVAS DE LAS SECRETARÍAS DE EDUCACIÓN}

RESUMEN

Este artículo trae parte de los resultados de una investigación que, desarrollada durante 2014 y 2015, buscó construir un diagnóstico sobre políticas educativas para la enseñanza media -especialmente las curriculares-, valiéndose para ello de informaciones recogidas en los estados brasileños y el Distrito Federal, los mayores responsables de la oferta de ese nivel de enseñanza. Los datos fueron recolectados por medio de: documentos y disposiciones legales vigentes; cuestionarios a los equipos responsables por ese nivel de enseñanza en las secretarías de educación de todos los estados del país; $y$ entrevistas cualitativas realizadas en una muestra de diez secretarías entre las 27. En este texto específicamente, el objetivo es presentar $y$ analizar algunas iniciativas que las entidades federadas han desarrollado para atraer y mantener a los jóvenes en ese nivel de enseñanza. 
ENSINO MÉDIO (EM) CONSTITUI-SE EM UMA ETAPA CRÍTICA NA FORMAÇÃO DOS indivíduos. Assume múltiplas funções, tais como a consolidação dos conhecimentos e habilidades básicas dos estudantes, a preparação para o ingresso no ensino superior ou no mercado de trabalho e a formação de cidadãos capazes de se engajar na sociedade. Resultados de uma pesquisa em 29 países apontam que $72 \%$ dos estudantes que começaram o ensino médio o completaram no tempo esperado (ORGANISATION FOR ECONOMIC CO-OPERATION AND DEVELOPMENT - OECD, 2014). ${ }^{1}$ Nesse contexto, é crescente a preocupação em relação aos estudantes que não recebem essa formação, situação que se traduz em problemas para os próprios indivíduos e para a sociedade na qual estão inseridos.

No Brasil, a obrigatoriedade do atendimento à população de 15 a 17 anos foi estabelecida pela Emenda Constitucional n. 59, em 2009, com previsão de ser implementada progressivamente até 2016 (BRASIL, 2009a), e consta da meta 3 do Plano Nacional de Educação (PNE) (BRASIL, 2014). De acordo com dados da Pesquisa Nacional por Amostra de Domicílios (Pnad), em 2015, 84,3\% dos jovens de 15 a 17 anos de idade estavam matriculados na escola. Fora dela, nessa mesma faixa etária, havia aproximadamente 1,6 milhão de pessoas, um desafio imenso ao cumprimento da meta na data prevista. Quando se considera a adequação da idade dos alunos à etapa de ensino em questão, o desafio torna-se ainda mais complexo - mesmo que o prazo de cumprimento seja maior. Na mesma meta 3 do PNE, definiu-se a elevação da taxa líquida de matrículas do 
ensino médio para $85 \%$ até o final do período de vigência do Plano, no ano de 2024. Em 2015, essa taxa era de 62,7\%, ou seja, apenas cerca de 60\% dos jovens de 15 a 17 anos estavam matriculados no ensino médio no país.

Além da matrícula, é preciso também garantir a permanência e conclusão do ensino médio com a qualidade adequada, de maneira que os estudantes se beneficiem por completo da formação aí recebida. No PNE, não foi incluída nenhuma meta em relação à permanência e à conclusão do ensino médio. No entanto, o movimento Todos Pela Educação propôs, como uma de suas metas, que pelo menos $90 \%$ dos jovens brasileiros de 19 anos deverão ter completado o ensino médio em 2022. De acordo com a Pnad, apenas 56,7\% dos jovens dessa idade haviam concluído o ensino médio no Brasil em 2014. Em relação à qualidade, o PNE utiliza o Índice de Desenvolvimento da Educação Básica (Ideb), composto pelo desempenho dos alunos em avaliações de língua portuguesa e matemática e por dados de fluxo escolar. A meta estabelecida pelo PNE busca alcançar um Ideb de 5,2 em 2024, sendo que, de 2011 até 2015, o resultado se manteve em apenas 3,7, abaixo da meta intermediária de 4,6 para este último ano. Ainda que o Ideb seja um indicador limitado da qualidade do ensino como um todo, seus resultados apresentam evidências de que, mesmo em áreas consideradas básicas, como leitura e resolução de problemas em matemática, os alunos que permanecem até o final do ensino médio estão apresentando níveis de aprendizagem distantes do esperado.

Analisando o quadro de desafios a serem enfrentados pelo ensino médio, Torres et al. (2013) afirmam que essa situação pode ser compreendida por meio de três abordagens não mutuamente excludentes. Os desafios decorrem: da massificação do ensino médio, especialmente depois da década de 1990, o que deve ser considerado com otimismo, sem que se perca de vista que a almejada ampliação do acesso não veio acompanhada de condições para garantir permanência e aprendizado; das indefinições, oscilações e fragmentação das políticas educacionais para esse nível de ensino, com projetos por vezes conflituosos entre si; e do desencontro crescente da escola com a cultura e a socialização juvenis, que têm passado por intensas transformações nas últimas décadas (TORRES et al., 2013). Há que se considerar, ainda, toda uma gama de fatores relacionados às condições de trabalho e à formação de professores, além da carência de docentes para esse nível de ensino (sobretudo nas áreas de matemática, física e química), situação que leva a um ensino truncado em seu desenvolvimento e descontínuo no que se refere às situações de aprendizagem, ensejando desinteresse, retenção e evasão dos alunos.

Apesar dessas múltiplas razões que impactam o ensino médio, é fato que o que se ensina e como se ensina têm sido apontados também 
como causas para o desinteresse e desmotivação dos jovens para permanecerem na escola. O discurso de que o currículo é desarticulado e inchado, com excesso de disciplinas e conteúdos enciclopédicos - o que dificulta o emprego de estratégias que favoreçam aprendizagens mais significativas e o atendimento das necessidades dos jovens de 15 a 17 anos -, está presente na mídia e na própria academia. A atual construção de uma base nacional comum, prevista inicialmente em uma das estratégias do PNE para ser pactuada entre todos os entes federativos até 2016, está em curso agora no Conselho Nacional de Educação (CNE). Mas a parte que se refere ao ensino médio foi suspensa em função da lei 13.415, sancionada em fevereiro de 2017, sobre a reforma do ensino médio. Esse processo de elaboração de um documento nacional norteador do currículo aumenta ainda mais a importância de se estudar aquilo que, de fato, tem sido proposto pelas redes estaduais em termos de políticas educacionais e, dentre elas, as relativas ao currículo.

Este artigo traz parte dos resultados de uma pesquisa ${ }^{2}$ que, desenvolvida durante 2014 e 2015, procurou construir um quadro diagnóstico e compreensivo a respeito das políticas educacionais para o ensino médio - especialmente as curriculares -, valendo-se, para tanto, de informações pesquisadas junto aos estados brasileiros e ao Distrito Federal. Para cumprir esses objetivos, os seguintes procedimentos foram adotados: levantamento bibliográfico das várias modalidades de ensino médio ofertadas pelas redes investigadas, bem como sobre currículos e disposições legais vigentes (nacionais e estaduais); questionários enviados às equipes responsáveis por esse nível de ensino nas secretarias de educação de todos os estados do país; entrevistas qualitativas realizadas junto a uma amostra de dez secretarias dentre as 27 , definida de modo a contemplar a diversidade existente no país (Ceará, Espírito Santo, Maranhão, Mato Grosso do Sul, Pará, Piauí, Roraima, Santa Catarina, São Paulo e Distrito Federal); por fim, entrevistas qualitativas também foram feitas com o responsável pelo ensino médio na Secretaria de Educação Básica (SEB) do Ministério da Educação (MEC) e também com a presidente do Conselho Nacional de Secretários de Educação (Consed), seguindo-se um roteiro previamente elaborado que buscava compreender as respectivas visões sobre o ensino médio. Na análise do material coletado, buscou-se fazer a chamada triangulação metodológica: leitura de textos acadêmicos e legislativos aliada a questionários, entrevistas e análise de documentos curriculares.

Pesquisa encomendada e patrocinada pela Fundação Victor Civita à Fundação Carlos Chagas: Ensino Médio: politicas curriculares dos estados brasileiros - Relatório Final (TARTUCE et al., 2015).

Cabe ressaltar que, como o objetivo da pesquisa não era refletir teoricamente sobre o tenso campo do currículo, mas sim analisar as políticas curriculares dos estados - tanto as mais amplas quanto aquelas consolidadas no documento curricular propriamente dito, nas quais há, evidentemente, uma concepção teórica que os embasa -, trabalhou-se 
com a concepção de currículo presente nas Diretrizes Curriculares Nacionais para o Ensino Médio (DCNEM):

O currículo é conceituado como a proposta de ação educativa
constituída pela seleção de conhecimentos construídos pela so-
ciedade, expressando-se por práticas escolares que se desdobram
em torno de conhecimentos relevantes e pertinentes, permeadas
pelas relações sociais, articulando vivências e saberes dos estu-
dantes e contribuindo para o desenvolvimento de suas identida-
des e condições cognitivas e sócio-afetivas. (BRASIL, 2012, Art. 6º)

Neste texto, o objetivo é apresentar e analisar algumas iniciativas que os entes federados têm desenvolvido para atrair e manter os jovens nesse nível de ensino, desafio que foi relatado por todas as secretarias de educação pesquisadas como um dos mais importantes a serem enfrentados. ${ }^{3}$ Para tanto, o artigo está estruturado em três partes, além desta introdução: na primeira, faz-se uma breve revisão da literatura que trata da relação dos jovens com a escola, tanto do ponto de vista das políticas públicas quanto de algumas pesquisas qualitativas realizadas sobre a temática; na segunda, apresentam-se os achados provenientes da pesquisa propriamente dita; por fim, fazem-se algumas considerações a respeito dos programas e políticas desenvolvidos pelos estados no sentido de atrair e manter os jovens em suas redes e discutem-se algumas questões decorrentes dessas ações, como as da diversificação, do tempo integral e da preparação para o ensino superior.

\section{ATRATIVIDADE DA ESCOLA DE ENSINO MÉDIO E RELAÇÃO COM JOVENS ESTUDANTES}

Todas as equipes das secretarias estaduais de educação entrevistadas afirmaram que atrair e manter os jovens no ensino médio é um dos desafios mais difíceis a serem enfrentados pela gestão pública. Esse desafio não é uma novidade para os pesquisadores do campo educacional: diversas investigações junto a jovens e escolas realizadas desde os anos 1990 têm enfatizado o distanciamento crescente entre esse público e a instituição escolar, indicando crise de seu papel enquanto agência de socialização e de ensino e aprendizagem para as novas gerações. Impulsionadas por essa discussão, as recentes políticas públicas nacionais para o ensino médio têm consolidado em seus documentos a necessidade de aproximar as escolas do universo juvenil.

A primeira a ser destacada é a própria Lei de Diretrizes e Bases da Educação Nacional (LDB), de 1996 (BRASIL, 1996), a qual concebe o ensino médio, pela primeira vez no país, como parte integrante da educação básica, ou seja, como formação escolar essencial à qual todo jovem deve

3

Os resultados da pesquisa incluem tanto análises das propostas curriculares propriamente ditas - expressas em documentos elaborados pelos respectivos estados e em discursos sobre a elaboração e a implementação curricular - quanto das políticas mais amplas destinadas ao ensino médio. Este artigo apresenta os achados relacionados a essas politicas mais amplas, e não ao documento curricular stricto sensu. 
ter acesso, independentemente de seu percurso posterior: a continuidade dos estudos e/ou o ingresso no mercado de trabalho (BRASIL, 1996). O reconhecimento legal e cultural a respeito da importância do ensino médio, como última fase da educação básica, veio acompanhado de muitos desafios a serem enfrentados:

\begin{abstract}
A democratização do acesso implicaria maior heterogeneidade do corpo discente. A mudança do perfil do alunado traria consequências para o currículo, para os métodos pedagógicos e para a formação dos professores, que iriam lidar com um público cada vez mais diverso e sem histórico familiar de frequência a esse nível de ensino. (SILVA et al., 2009, p. 10)
\end{abstract}

As novas DCNEM, ${ }^{4}$ de 2012 , incorporam o pressuposto de que a juventude do país é diversa. De fato, o Parecer que as embasa (BRASIL, $2011)^{5}$ justifica a necessidade de uma nova diretriz, em razão da(s):

- novas exigências educacionais resultantes das transformações na produção de conhecimento e no acesso às informações, no mundo do trabalho e nos próprios interesses dos jovens estudantes;

- diversidade desses jovens, o que implica "reconhecer diferentes caminhos de atendimento aos variados anseios das 'juventudes' e da sociedade". (BRASIL, 2011, p. 4)

Esse Parecer entende que a educação de boa qualidade deve levar à superação das desigualdades educacionais, algo que só pode ser conquistado se todos tiverem oportunidades iguais de acesso ao conhecimento. Para que isso ocorra, esse documento orientador defende que "a escola deve ser menos rígida, segmentada e uniforme, a fim de que os estudantes, indistintamente, possam adequar seus tempos de aprendizagens de modo menos homogêneo e idealizado" (BRASIL, 2011, p. 9). Nesse sentido, o Parecer indica a importância de reforçar o projeto político-pedagógico das escolas, "de modo a permitir diferentes formas de oferta e de organização, mantida uma unidade nacional" (BRASIL, 2011, p. 4). Sugere, assim, a necessidade de um projeto que contemple princípios e objetivos comuns para o ensino médio, sobre o qual podem

Resolução CNE/CEB n. 2 de 30 de janeiro de 2012 (BRASIL, 2012). As DCNEM de 2012 substituem as DCNEM de 1998 existir possibilidades diversas:

A definição da identidade do Ensino Médio como etapa conclusiva da Educação Básica precisa ser iniciada mediante um projeto que, conquanto seja unitário em seus princípios e objetivos, desenvolva possibilidades formativas com itinerários diversificados que contemplem as múltiplas necessidades socioculturais e econômicas dos 
Antes das DCNEM/2012, que contêm os princípios e procedimentos a serem seguidos por sistemas de ensino e escolas que o oferecem, o MEC já havia lançado o Programa Ensino Médio Inovador (ProEMI). Em linhas gerais, o ProEMI propõe-se a induzir a reestruturação curricular e pedagógica nas escolas de ensino médio, por meio de repasse de recursos financeiros para que as escolas coloquem em prática seus Projetos de Redesenho Curricular (PRCs), elaborados com essa finalidade e seguindo os requisitos estabelecidos pelo Programa (BRASIL, 2009b). Partindo da ideia de que as instituições escolares e sua comunidade são as instâncias mais capacitadas para definir seu currículo conforme sua realidade, a União objetiva incentivar propostas inovadoras “capazes de disseminar nos respectivos sistemas a cultura de um currículo dinâmico, flexível e compatível com as exigências da sociedade contemporânea" (BRASIL, 2009b, p. 3). Em termos curriculares, a primeira versão do programa propõe um modelo de ensino médio que "ganhe identidade unitária e que assuma [...] formas diversas e contextualizadas" (BRASIL, 2009b, p. 4), para contemplar a autonomia das escolas e a heterogeneidade dos estudantes. O Programa vai, assim, na mesma direção das Diretrizes, ao se preocupar com um currículo capaz de promover uma aprendizagem que faça sentido para os jovens adolescentes e de favorecer a interlocução da escola com as culturas juvenis.

Todavia, esses programas e políticas educacionais destinados ao ensino médio, que buscam - dentre vários outros - melhorar o acesso a e a permanência do aluno em uma escola de boa qualidade, ainda estão longe de cumprir as finalidades formativas estabelecidas pela LDB/96: consolidação dos conhecimentos adquiridos no ensino fundamental (EF), aprofundamento da compreensão dos fundamentos científico-filosóficos dos processos produtivos, preparação básica para o trabalho, formação para a cidadania, para o pensamento crítico e para a autonomia intelectual (BRASIL, 1996). Ao contrário, desde os anos 1990, inúmeras pesquisas têm mostrado o distanciamento crescente entre o universo juvenil e o escolar. Investigações sobre os sentidos da escola de ensino médio para os jovens brasileiros têm sido recorrentes e trazem uma gama variada de achados.

Dois balanços foram produzidos sobre a temática da juventude: o primeiro, ${ }^{6}$ já no final dos anos 1990, analisou a produção discente sobre juventude e escolarização, por meio do levantamento das dissertações e teses defendidas nos programas de pós-graduação em educação, no período de 1980-1998 (SPOSITO, 2002); o segundo foi mais abrangente, tanto do ponto de vista da temática - juventude em geral, ligada a vários subtemas e não apenas à escolarização - quanto das áreas 
abordadas: $^{7}$ educação, ciências sociais (antropologia, ciência política e sociologia) e serviço social, e buscou estabelecer, quando possível, continuidades e transformações no que se refere a perspectivas teórico-metodológicas e problemáticas envolvidas, nos dois períodos (SPOSITO, 2009).

No primeiro estado da arte, que teve nos jovens e estudantes seu principal objeto de estudo, verificou-se que, na distribuição da produção sobre a temática da juventude, segundo temas dominantes, 12,9\% referiam-se a "juventude e escola". Escrevendo sobre essa questão, Juarez Dayrell (2002, p. 71) revelava, à época, que essas investigações em geral reduziam a educação à instituição escolar, como se esta fosse "agência exclusiva de socialização, sem estabelecer relações com outros agenciamentos socializadores que tecem a experiência de adolescentes e jovens fora da escola”. Além de a escola ter centralidade na análise e universo empírico, os jovens eram vistos apenas por sua condição de alunos. Para ampliar essa perspectiva, especialmente em um contexto de crise dessa instituição, Sposito (2003) propôs - em artigo que se tornou clássico na área - "uma perspectiva não escolar no estudo sociológico da escola".

Considerar o que ocorre com os jovens fora da escola e incorporar a categoria juventude à discussão significa justamente levar em conta que eles trazem experiências de várias outras esferas que os constituem como jovens e não podem ser desprezadas pela instituição escolar. Os jovens possuem formas de pertencimento com grupos de pares (constituindo por vezes grupos de culturas juvenis) e de expressão e de lazer (musicais, visuais, corporais, etc.), propiciadas por outros espaços socializadores e redes dispersas que não se apagam quando eles estão na escola (SPOSITO, 2006). Mansutti (2011) salienta, assim, que a escola não é o único espaço de aprendizagem para os jovens, especialmente

Estado da arte sobre juventude na pós-graduação brasileira: educação, ciências sociais e serviço social (1999-2006) também coordenado por Marilia Sposito (2009).

Esse tema ocupava o quinto lugar na frequência de eixos temáticos na área da educação e, juntamente com as temáticas sobre "Jovens, trabalho e escola" e "Jovens universitários", representava mais de $47 \%$ da produção pesquisada No balanço posterior quando se olha a produção discente apenas na área da educação, a participação individual da categoria "Jovens e escola" até cresce (passando a 17,8\%), mas, no conjunto, há arrefecimento de estudos dedicados às trajetórias escolares de jovens e introdução de novos assuntos nas pesquisas desenvolvidas. na contemporaneidade: as novas gerações circulam por múltiplos tempos e espaços, pela via real ou virtual, como nos hipertextos e recursos multimídia, que viabilizam comunicação e informação. Elas são, assim, “portadoras de uma nova racionalidade cognitiva, uma racionalidade pautada em apropriação de conhecimentos e em ganhos de aprendizados de forma difusa e descentrada” (MANSUTTI, 2011, p. 71). Para a autora, essa experimentação e circulação em vários territórios aos quais os jovens têm acesso representam ganhos de aprendizado:

As práticas que ocorrem fora da instituição escolar devem chamar a atenção dos educadores, não para trazer a rua para o interior da escola, esvaziando a especificidade dos processos que ocorrem em seu âmbito. Mas é preciso reconhecer e compreender esse universo se quisermos, de algum modo, transformar a ação educativa da escola, quanto mais não seja pelo melhor conhecimento dos sujeitos aos quais se destinam os esforços dos educadores. (SPOSITO, 2006, p. 101) 
Na análise sobre a temática "jovens e escola” no novo estado da arte produzido, Dayrell et al. (2009) concluem que, comparativamente ao balanço anterior, houve, nas novas pesquisas, ampliação das temáticas abordadas e das perspectivas teórico-metodológicas a elas aplicadas, justamente no sentido de abordar temas afeitos ao universo escolar a partir de um prisma que ultrapassa o espaço exclusivo da instituição. Os autores citam como exemplos dessa maior abrangência os estudos: do sucesso e fracasso escolar por meio dos processos que os produzem, com olhar especial sobre as famílias; da violência e da indisciplina na escola, observando-se as relações que mantêm com as violências praticadas fora dela; das culturas juvenis e das múltiplas identidades dos jovens, considerando-se aí aspectos da diversidade, como as relações de gênero e etnicorraciais. Toda essa ampliação não significa, porém, que as escolas brasileiras tenham conseguido, elas mesmas, ampliar a visão que têm de seus alunos.

Ao contrário, diversos estudos revelam que "as escolas se mostram pouco abertas a desenvolver atividades que vão além da transmissão dos conteúdos formais” (DAYRELL; GOMES; LEÃO, 2010, p. 248). Em pesquisa realizada sobre as possibilidades de diálogo com jovens em uma instituição escolar da região metropolitana de Belo Horizonte, esses autores concluem "que parece haver um choque cultural, geracional e um desrespeito ao aluno como sujeito social e cidadão de direitos no interior das escolas" (DAYRELL; GOMES; LEÃO, 2010, p. 249), indo ao encontro do que Zibas, Ferretti e Tartuce (2004, p. 114-115) detalharam seis anos antes:

\footnotetext{
Os professores têm, em geral, grande dificuldade de se aproximar da cultura juvenil, pois ela é portadora de uma linguagem estranha ao mundo escolar e exprime necessidades e expectativas que a escola não reconhece como válidas. Esse distanciamento afunila a cultura da escola, empobrece as trocas entre os sujeitos da trama institucional e converte, muitas vezes, o conteúdo das disciplinas em elemento aversivo aos alunos.
}

Esse quadro de distanciamento entre a escola e o universo juvenil certamente tem repercussões sobre as percepções dos jovens em relação ao sentido que encontram na escola de ensino médio e sobre as motivações que os fazem ou não nela permanecer. No que se refere às relações entre a escola e o saber, entre os jovens e o conhecimento, pesquisas (ABRAMO; BRANCO, 2005; CENTRO DE ESTUDOS E PESQUISAS EM EDUCAÇÃO, CULTURA E AÇÃO COMUNITÁRIA - CENPEC; INSTITUTO DE ASSESSORIA E PESQUISA EM LINGUAGEM - LITTERIS 2001) têm apontado a ambiguidade presente nessa relação: jovens que acreditam que o conhecimento escolar lhes será útil no futuro - e esse futuro 
geralmente se refere à conquista de um emprego - e, ao mesmo tempo, que não lhe atribuem um valor intrínseco, revelando tanto descrença na capacidade de a escola impactar suas vidas no presente quanto uma relação instrumental com o conhecimento:

\begin{abstract}
Eles [...] depositam confiança na escola, em relação ao projeto futuro, mas as relações são mais difíceis e tensas com o tempo presente, na crise da mobilidade social via escola. Configura-se, desse modo, uma ambiguidade caracterizada pela valorização do estudo como uma promessa futura e uma possível falta de sentido que encontram no presente. Nessa tensão, pode ocorrer uma relação predominantemente instrumental com o conhecimento, resposta mínima para se evitar a deserção ou o retraimento total em relação ao processo de sua apropriação. (SPOSITO, 2005, p. 124)
\end{abstract}

No decorrer dos anos 2000, os estudos sobre expectativas dos jovens em relação à escola continuaram oscilando entre representações mais ou menos positivas, no tempo presente ou futuro, geralmente atreladas à crença de um possível efeito da escola na inserção no mercado de trabalho e conquista de um emprego melhor. No fim da década, Tartuce (2010) revela que essa positividade da escola como meio de mobilidade social para jovens das classes populares transfere-se do ensino médio para a educação superior, da escola para a universidade. Comparando a transição da escola ao trabalho entre esses jovens e aqueles de origem social mais elevada, a autora mostra que, para os primeiros, a experiência escolar, mesmo sendo mais instrumental, não é transformada em algo positivo para fazer a passagem ao trabalho:

Enquanto a maioria [dos jovens de origem social mais elevada] afirma ter tido na escola uma sólida formação (sendo a maior parte dessas afirmações referida à escola particular), que os deixa mais seguros para enfrentar os processos seletivos, os jovens [das classes populares] têm péssimas recordações da escola que cursaram, em geral pública: "o inglês é só o one, two, three e o verbo to be, que é só isso que aprende na escola [pública]" contrapõe-se ao "aprendi a escrever bem, a falar bem inglês, tudo isso ai foi influenciando", revelado por jovem que sempre estudou em escola particular de alto padrão. Na maioria dos casos, é como se os jovens das escolas particulares as encarassem como uma instituição, que transmite saberes e os ajuda em seu processo de socialização e de integração; já para a maioria daqueles que fizeram escola pública, aquilo que dela se recorda positivamente em geral está ligado a algum/a professor/a que marcou suas vidas de alguma forma. (TARTUCE, 2010, p. 237-238) 
Assim, mesmo considerando que, no Brasil, o sistema educativo enfatiza uma formação acadêmica mais geral no ensino médio, ou seja, com menores vínculos entre escola e trabalho (HASENBALG ${ }^{9}$ apud TARTUCE, 2010), os resultados em termos de experiências e de sentidos atribuídos pelos jovens e de possibilidades relativas à sua inserção no mercado de trabalho variam muito conforme o tipo de escola frequentada, se pública ou privada. É claro que há excelentes escolas públicas e instituições particulares de qualidade duvidosa; e, se é fato que há uma crise de sentidos da escola em geral e um distanciamento da instituição do universo juvenil, diversas pesquisas que esmiuçaram o cotidiano da relação de jovens com escolas públicas brasileiras indicam que essa relação - seja no tempo presente ou em termos de expectativas de futuro - tem se deteriorado significativamente. ${ }^{10}$

Desse modo, a questão da permanência no ensino médio coloca-se como um grande desafio, e novos estudos sobre os motivos que levam os jovens a desistir da escola intensificaram-se a partir de meados dos anos 2010. O que acontece, então, ao longo da vida escolar de grande parcela dos estudantes brasileiros para que eles cheguem aos 19 anos de idade sem nem concluir o ensino médio? Utilizando dados da Pnad 2012 para responder a essa pergunta, Simões (2014) mostra que os maiores percentuais de evasão ocorrem no segundo ciclo do ensino fundamental $(\mathrm{EF}):^{11}$ de todos os jovens que ingressaram na $1^{\text {a }}$ série do EF, $21 \%$ evadiram até o final dessa etapa (19\% nos anos finais do EF), $9 \%$ o fizeram na transição entre o EF e o EM, e 13\% deixaram a escola durante o EM. É justamente nessa etapa - nos anos finais do EF - que se encontram as maiores diferenças entre as taxas de evasão de ricos e pobres, levando o EM a trabalhar com um público bem mais restrito em termos socioeconômicos que o EF: dentre os $20 \%$ de jovens mais pobres, $37 \%$ evadiram-se até o final do EF (32\% no segundo ciclo do EF), 17\% na transição e 15\% durante o EM.

Ainda que menores que as do EF, as taxas de evasão na transição para o EM - e durante seu decorrer - também levantam preocupações acerca dos motivos que levariam os jovens a não prosseguir até sua conclusão. Embora já receba menos alunos de baixa renda que o EF, o EM continua o processo de seleção com viés socioeconômico: também nele a evasão escolar é tanto mais forte quanto mais pobre for a família. Assim sendo, supõe-se que algumas das razões para a evasão estejam ligadas a questões socioeconômicas.

Uma das principais hipóteses levantadas é a de que as condições de pobreza forçariam os jovens a desistir dos estudos para trabalhar. Dados da Pnad 2011, apresentados por Torres et al. (2013), mostram que, dentre aqueles que se evadiram da escola, a maioria não trabalha $(61,7 \%)$ e, ainda, que quanto menor a renda, maior a chance de não trabalhar. Esses dados, portanto, enfraquecem a hipótese de que a principal razão

9

HASENBALG, C. A

Transição da escola ao mercado de trabalho. In: HASENBALG, Carlos; SILVA, Nelson V. Origens e destinos: desigualdades sociais ao longo da vida. Rio de Janeiro: Topbooks, 2003. p. 147-72.

10

No segundo estado da arte sobre juventude, Dayrell et al. (2009, p. 106) escrevem que "o jovem tematizado pelas pesquisas é, em sua maioria, urbano, oriundo das camadas populares e estudante de escola pública. Apesar da ampliação relativa do número de trabalhos que pesquisam jovens de classe média e estudantes de escola particular, ainda existe uma lacuna no conhecimento deste setor da população juvenil".

11

Esse, porém, é um segmento pouco estudado. Os imensos desafios enfrentados pelo país nessa etapa da educação básica podem ser encontrados no estudo Anos finais do ensino fundamental: aproximandose da configuração atual (DAVIS et al., 2012). 
para os jovens pobres abandonarem a escola está relacionada ao trabalho. Do mesmo modo, a gravidez precoce é também apontada como possível causa para o abandono das meninas. O mesmo estudo indica que, embora a proporção de alunas que tiveram filhos dentre as que evadiram seja elevada (34,4\%), essa situação não é predominante e, portanto, não parece ser a principal causa de abandono das meninas. Os dados sugerem que, embora o trabalho e a gravidez precoce guardem associação com a evasão escolar no ensino médio, eles provavelmente não são as causas exclusivas ou preponderantes do fenômeno (TORRES et al., 2013). ${ }^{12}$

Esse estudo, assim como pesquisa da United Nations Children's Fund (Unicef) (2014), apresenta opiniões de jovens de baixa renda sobre as escolas, contribuindo para a compreensão das possíveis causas do desinteresse e da evasão escolar: a infraestrutura precária dos estabelecimentos, a desmotivação e as condições de trabalho dos professores, a indisciplina dos alunos e a falta de diálogo entre eles, professores e a gestão da escola, assim como a violência existente no cotidiano escolar, são todos aspectos apontados como fatores de descontentamento dos estudantes. Além disso, os alunos salientaram que os conteúdos são desinteressantes, distantes de sua realidade (TORRES et al., 2013; UNICEF, 2014).

Mais recentemente, duas publicações de peso - produzidas ao tempo em que esta pesquisa também era finalizada - retomam vários temas que vêm sendo pesquisados desde os anos 2000, enriquecendo o debate sobre as múltiplas e interdependentes questões afeitas ao ensino médio e às juventudes: em 2015, ampla e representativa pesquisa realizada com 8.283 jovens desse nível de ensino nas cinco regiões do país foi compilada e divulgada no livro Juventudes na escola, sentidos e buscas: por que frequentam? (ABRAMOVAY, 2015); em 2016, número temático da revista Educação e Realidade trouxe artigos com abordagens e metodologias variadas sobre: demanda, oferta e direito à educação (CORTI, 2016); trajetórias educativas (FILARDO, 2016) e transição para a vida adulta (LARANJEIRA; IRIART; RODRIGUES, 2016); sentidos da escola e projetos de vida (KLEIN; ARANTES, 2016; PEREIRA; LOPES, 2016); o ensino médio integrado ao técnico (SALES; VASCONCELOS, 2016), entre outros.

Na confluência desses estudos, (re)aparece fortemente a necessidade de a instituição escolar considerar outros aspectos que influenciam os jovens em processo de escolarização (como família e trabalho) e os múltiplos saberes que eles produzem fora do ambiente escolar (sejam eles parte ou não de uma cultura juvenil específica), de modo que ela vão ao encontro de alguns estudos que, já na década de 1980, mostravam que eram os mecanismos internos às escolas os responsáveis pelas altas taxas de evasão dos alunos (MADEIRA, 1986). possa produzir socialização e aprendizagens significativas. Esse reconhecimento vai ao encontro do consenso de que o ensinar não pode ser constituído pela mera transmissão de conhecimentos, já que os saberes escolares não têm motivado os alunos, os quais, contrariamente, mantêm com eles uma sensação de estranhamento. Por outro lado, algumas dessas novas pesquisas também trazem percepções positivas de 
estudantes que reconhecem e valorizam as experiências escolares e os professores, apesar de todas as adversidades: "em muitas falas [dos jovens entrevistados], a obrigação, o saber e o lúdico não são excludentes, o que decola principalmente de relações gratificantes com professores e de boas aulas” (ABRAMOVAY, 2015, p. 233). Tal percepção é ratificada por Mesquita (2016), que, por meio de questionários, entrevistas e observação do cotidiano e de salas de aula de uma escola de ensino médio no Rio de Janeiro, busca identificar as características e os saberes específicos dos docentes desse nível de ensino. Interpretando as diversas lógicas de ação desses profissionais, conclui que as dimensões motivacionais e relacionais destacam-se - dentre as categorias elaboradas - como aquelas centrais para uma ação docente competente e bem-sucedida, conferindo "aos professores deste segmento de ensino o papel de construtores de sentido e de um profissional das relações, capaz de interagir com os jovens, mobilizá-los para aprender, permitindo sua participação e envolvimento” (MESQUITA, 2016, p. 25, grifos da autora).

Por fim, há ainda toda uma série de temas que não são diretamente tratados pelas investigações descritas, mas de algum modo apontados como impactantes na relação dos jovens com a escola: infraestrutura das instituições, questões curriculares e formação inicial e continuada de professores.

Essa breve revisão de literatura sobre jovens e ensino médio evidencia, mais uma vez, a complexidade das questões educacionais. Fica claro que discussões sobre acesso, permanência e qualidade do ensino médio - atualmente traduzidas e qualificadas como falta de direito à escolarização, abandono, repetência e desencanto com o saber e com as relações tecidas na escola - requerem uma visão integrada das dimensões macrossocial e microssocial, que envolvem "as cotidianidades, a micropolítica [...], subjetividades, frustrações” (ABRAMOVAY, 2015, p. 231). $\mathrm{Na}$ articulação das pesquisas acadêmicas com as políticas públicas, essa complexidade demanda que elas sejam relacionadas e incidam em diversas frentes simultaneamente. Todavia, essa coerência é muito difícil de ser alcançada, pois, na maior parte das vezes, é preciso escolher focos prioritários de ação. Assim, consciente de toda a complexidade que envolve e questão, este artigo pretende contribuir para a compreensão de um dos aspectos que tem sido responsabilizado pela baixa atratividade da escola para os jovens, qual seja, o desenho curricular do ensino médio. A seguir, serão apresentadas algumas iniciativas relacionadas direta ou indiretamente aos currículos que objetivam atrair e manter os jovens na escola nos dez estados deste estudo. ${ }^{13}$ 


\section{CARACTERIZAÇÃO DA OFERTA E INICIATIVAS PARA ATRAIR E MANTER OS JOVENS NAS ESCOLAS DE ENSINO MÉDIO NAS REDES ESTADUAIS PESQUISADAS}

Se existem desafios para atrair os jovens para as escolas e garantir que concluam o ensino médio com a qualidade desejada, ao analisar o perfil da oferta dessa etapa nas redes pesquisadas (Ceará, Espírito Santo, Maranhão, Mato Grosso do Sul, Pará, Piauí, Roraima, Santa Catarina, São Paulo e Distrito Federal), percebe-se que esses desafios são ainda maiores para algumas unidades da federação.

De acordo com dados da Pnad 2014 (INSTITUTO BRASILEIRO DE GEOGRAFIA E ESTATÍSTICA - IBGE, 2015), há uma grande variação entre os estados em relação à população de 15 a 17 anos que está matriculada no ensino médio com a idade esperada: as taxas de escolarização líquida ${ }^{14}$ variam, nas redes pesquisadas, de 47\% no Pará até 76\% em São Paulo. Isso indica que, apesar de terem taxas semelhantes de atendimento aos alunos de 15 a 17 anos (todas acima de 75\%), os estados possuem situações bem distintas no que se refere ao atraso escolar, uma situação que incide na proporção de jovens que estão na escola na etapa correta.

$\mathrm{O}$ atraso escolar e o abandono da escola também têm efeito nas taxas de conclusão do ensino médio na idade adequada, de modo que se observam consideráveis variações entre os estados pesquisados. Se, no Distrito Federal (DF), 73\% dos jovens concluem o ensino médio até os 19 anos, nem 38\% deles o fazem no Pará - quase a metade da taxa do DF.

Do mesmo modo, sabe-se que as redes de ensino pesquisadas diferem em termos de tamanho, um fator que certamente impacta várias outras características da oferta de ensino médio. ${ }^{15}$ Conforme dados do Censo Escolar da Educação Básica de 2015 (BRASIL, 2016), enquanto as redes de Roraima e do Distrito Federal têm, respectivamente, 144 e 217 escolas que oferecem o ensino médio, a do Maranhão conta com 1.030. São Paulo, por sua vez, destoa consideravelmente dos demais estados pesquisados, com um total de 6.445 escolas que contemplam esse nível de ensino.

A taxa de escolarização líquida indica o percentual da população em determinada faixa etária matriculada no nível de ensino adequado a essa faixa etária.

Em termos de turnos, a maioria das matrículas do ensino médio, em todos os estados, concentra-se nos períodos matutino e vespertino. O Distrito Federal tem a rede com o menor percentual de matrículas no ensino noturno, com apenas $11 \%$ delas, enquanto no Piauí praticamente 40\% das matrículas do ensino médio estão no noturno, apresentando o maior percentual. Maranhão, Mato Grosso do Sul, Pará, Santa Catarina e São Paulo têm todos mais de 30\% das matrículas nesse período. Em São Paulo, esse percentual representa 966.320 alunos, de acordo com o Censo Escolar da Educação Básica de 2014 (BRASIL, 2015). 
De um modo geral, pode-se dizer que todas as redes, a despeito de suas diferenças, informaram que um dos principais desafios com que se deparam é o de aproximar os jovens do contexto escolar, motivá-los e mantê-los na escola. Assim, muitos esforços são feitos para desenvolver diferentes formas de organização, programas, modalidades e ênfases dadas ao ensino médio.

Consoante ao novo PNE, a política da escola em tempo integral é uma tendência em quase todos os estados investigados. Em alguns deles, como no Piauí, as escolas em tempo integral contam com docentes em regime de dedicação exclusiva, situação que, ainda que implique aumento de custo, segundo os entrevistados, permite que os professores tenham maior conhecimento e envolvimento com os alunos e com a comunidade, alcançando melhores resultados escolares.

Nas escolas em tempo integral, em muitos locais, as disciplinas básicas são dadas de manhã e, à tarde, são feitas atividades complementares. Esse é o caso de um dos modelos de escola integral de São Paulo, o Escola de Tempo Integral (ETI) - presente em 236 escolas à época. Nesse modelo, no contraturno, os estudantes frequentam atividades esportivas e culturais. O segundo tipo de escola integral em São Paulo é o Novo Modelo de Escola Integral (envolvendo 257 escolas à época), no qual os estabelecimentos estão tentando uma nova organização disciplinar que venha a ocupar todo o período integral. O currículo desse modelo envolve as 11 disciplinas da base comum, aquelas da parte diversificada (língua estrangeira, disciplinas eletivas e práticas de ciências) e ainda as 800 horas de atividades complementares (orientação de estudos, projeto de vida, mundo do trabalho e preparo acadêmico), distribuídas ao longo dos dois períodos.

É perceptível, nas entrevistas, que as redes consideram as escolas de tempo integral boas alternativas para atrair e manter o jovem na escola. Percebe-se que há, na representação dos gestores e também no ideário dos documentos, uma convicção de que a permanência integral na escola ofereceria condições mais propícias para uma formação mais completa, "na medida em que se podem fundir conhecimentos/conceitos educacionais, artísticos e culturais, de saúde, do mundo do trabalho, com vistas a uma visão mais abrangente do próprio ato de aprender" (MARANHÃO, 2014, p. 17).

Enquanto as entrevistas apontam para a defesa da adoção de escolas de tempo integral por parte dos gestores, também revelam que esse tipo de política tem encontrado resistência das comunidades locais. No Mato Grosso do Sul, por exemplo, alunos e pais posicionaram-se contra as escolas em tempo integral: os primeiros porque não queriam ser obrigados a passar mais tempo na escola; os segundos porque o tempo integral inviabilizaria eventuais trabalhos para seus filhos. Segundo os entrevistados, quando a comunidade percebeu que essas escolas, depois 
de um ciclo de três anos, começaram a obter melhores resultados no Ideb, as oposições diminuíram. Nesse sentido, o Ceará aposta em uma estratégia negociada de implementação tanto das escolas em tempo integral quanto do ensino médio integrado à educação profissional. A Secretaria de Educação tem promovido discussões a respeito dos interesses e necessidades das comunidades escolares para as quais pretende expandir esses tipos de oferta, em uma tentativa de alinhar as ações da Secretaria às diversas aspirações de cada coletividade, antes de promover as mudanças pretendidas.

Embora as matrículas em tempo integral nos vários níveis da educação básica tenham, segundo o censo escolar, mais que triplicado de 2010 a 2015, essa oferta ainda não atingiu grandes proporções no ensino médio das redes pesquisadas. O maior número de matrículas do ensino médio em tempo integral está em São Paulo (cerca de 68 mil), seguido pelo Ceará (cerca de 47 mil matrículas). Este último estado tem também o maior percentual de matrículas do ensino médio em tempo integral: $14 \%$ delas. Na outra ponta, as redes do Distrito Federal, do Espírito Santo, do Pará e de Roraima não chegam a ter 1\% de matrículas em tempo integral.

Se existem críticas ao ensino médio em tempo integral em diversas localidades, a oferta de educação profissional é, por sua vez, justificada nas redes como uma demanda proveniente da própria sociedade e particularmente dos jovens. Ao tratar da modalidade de ensino médio integrado à educação profissional, os entrevistados afirmam que, em geral, essa oferta vai ao encontro do desejo dos jovens de antecipar a formação profissional enquanto cursam, simultaneamente e na mesma instituição, o ensino médio. A modalidade atende também a demandas locais por profissionais qualificados. Em Santa Catarina, a Secretaria realizou, em parceria com as universidades, um estudo estratégico das regiões do estado, buscando avaliar em quais delas havia demanda por uma formação técnica e quais cursos seriam mais pertinentes. Na cidade de São Joaquim, por exemplo, foram abertos cursos de vitivinicultura, horticultura, fruticultura e floricultura.

Todos os técnicos das secretarias deram ênfase, porém, ao fato de que a formação técnica não pode ser reduzida a uma profissionalização estreita. Ao contrário, ela deve ser ampla e integrada, no sentido de propiciar a formação para a cidadania e permitir a continuidade dos estudos, possivelmente nas universidades. Todas as instituições em que há essa modalidade de ensino médio devem oferecer a mesma base comum, acrescida da parte específica. Se a instituição é em tempo integral, a base comum é dada frequentemente no período matutino, ficando a tarde dedicada à formação profissional ou vice-versa. Em outros casos, há a tentativa de intercalar as disciplinas gerais e as específicas em um mesmo período. 
As modalidades com maior oferta nos estados pesquisados são o ensino médio integrado à educação profissional e o curso técnico subsequente ao ensino médio. O estado com maior número de matrículas na educação profissional integrada ao ensino médio é o Ceará, com cerca de 44 mil matrículas. Enquanto isso, o Distrito Federal e Roraima têm em torno de 500 matrículas nessa modalidade. São Paulo, por sua vez, oferece o maior número de matrículas nos cursos técnicos concomitantes e subsequentes ao ensino médio, com cerca de 40 mil e $93 \mathrm{mil}$ matrículas, respectivamente. Porém, ainda que os números da rede paulista sejam expressivos se comparados aos dos outros estados, dado o imenso tamanho da rede, a oferta de educação profissional representa apenas acerca de $11 \%$ do número de matrículas de ensino médio da rede estadual.

Apesar do reconhecimento da demanda - e da legitimidade do ensino médio integrado e da educação profissional como etapa final da educação básica, percebe-se forte ênfase no ensino médio como momento preparatório para o ingresso no ensino superior. Nessas circunstâncias, o Exame Nacional de Ensino Médio (Enem) ganha, consequentemente, enorme destaque, por suas notas serem empregadas como parte do processo seletivo para o ingresso nas universidades federais e como parte dos critérios para se candidatar a uma bolsa do Programa Universidade Para Todos (ProUni) ou a um financiamento do Fundo de Financiamento Estudantil (Fies).

Nenhum estado afirma explicitamente que trabalha apenas para atender ao que é exigido pelo Enem: para muitas unidades federativas, o ensino superior é uma dentre as várias opções de futuro oferecidas aos jovens. Como afirmou uma das entrevistadas no Maranhão, “a universidade é uma das opções. Queremos um aluno formado para a vida, na perspectiva da formação integral, para que ele faça suas escolhas". Nos estados analisados, a tônica na educação superior é implícita: "se eu (a Secretaria) formar com qualidade, ele (o aluno) vai ser um cidadão, poderá ir para a universidade”, disse a Coordenadora do Ensino Médio do Distrito Federal.

Entretanto, em alguns estados, a preparação dos alunos para o ingresso no ensino superior foi apresentada como opção prioritária nas entrevistas. No Pará, por exemplo, descreveu-se que os vestibulares das universidades públicas existentes à época (uma federal e outra estadual) pautaram a definição dos conteúdos que compõem a Proposta Curricular de 2003 (PARÁ, 2003). No Mato Grosso do Sul, afirmou-se claramente que o ensino médio regular é o foco principal do interesse dos alunos, pois eles querem ter bons resultados no Enem e ingressar no ensino superior.

Não sem razão, portanto, a maioria dos estados pesquisados oferece projetos específicos de preparação para os exames de ingresso no 
ensino superior e, em especial, para o Enem, caso do Ceará, Espírito Santo, Maranhão, Mato Grosso do Sul, Pará, Roraima, Santa Catarina e São Paulo. Geralmente, os cursos são voltados para alunos que estão matriculados no ensino médio em escolas da rede pública, mas muitos também aceitam seus egressos e inclusive alunos da rede privada. A maioria desses projetos proporciona aulas presenciais nas escolas, seja no contraturno ou aos finais de semana, situação descrita, por exemplo, pelo Pará e Mato Grosso do Sul. Alguns desses cursos já são ofertados há bastante tempo, como em Santa Catarina, cujo programa existe há mais de 10 anos. Alguns estados contam com cursos on-line, como São Paulo e Maranhão, havendo, neste último, interatividade em tempo real. Além de cursos propriamente ditos, alguns estados, como o Espírito Santo, ainda disponibilizam materiais de apoio, na forma de orientações, exercícios e provas simuladas.

Embora tenha sido percebida nas redes pesquisadas uma ênfase na preparação para o ensino superior e a universalização do Enem tenha sido definida como uma das metas do PNE, ainda não se pode dizer que ela se traduz em participação maciça de alunos dos estados investigados nos vestibulares - pelo menos não no Enem, para o qual há dados para todo o país. Em todos os estados visitados, mais de $80 \%$ dos alunos do $3^{\circ}$ ano das redes privadas de ensino participaram desse exame em 2012, ${ }^{16}$ seja no Maranhão e no Pará, seja até mesmo em São Paulo. Já nas redes públicas, o percentual dos alunos do $3^{\circ}$ ano que realizaram essa prova não ultrapassou 50\%. Em outros estados, como o Espírito Santo e o Ceará, as taxas de participação da rede pública no Enem já estavam mais próximas às da rede privada: $88 \%$ e $82 \%$, respectivamente.

Além de programas voltados para preparar os alunos para enfrentar os vestibulares, boa parte das redes pesquisadas afirmou empreender esforços para desenvolver diferentes formas de organização curricular para o ensino médio, no intuito de obter dos jovens um maior envolvimento e comprometimento com os estudos. O ensino médio organizado em semestres é forma curricular adotada pelo Distrito Federal (DF), na tentativa de melhorar a relação professor-aluno, promover a permanência do corpo discente na escola e aprimorar sua aprendizagem. No DF, a semestralidade foi inicialmente pensada para o ensino noturno. Em 2012, tentou-se fazer dela uma política para toda a rede, mas, diante da resistência de algumas escolas, a semestralidade foi implan-

O dado mais recente encontrado é de 2012 Considerando o crescimento do número de participantes do Enem ao longo dos anos, é bem provável que todas as taxas apresentadas nesse trecho tenham aumentado até a última edição do exame. tada por adesão: das 89 escolas de ensino médio existentes em 2013, 43 delas, nesse mesmo ano, adotaram essa proposta. Cabe ressaltar que, se a matrícula é anual para o aluno, a organização é semestral: "os componentes curriculares foram divididos em dois blocos, que devem ser ofertados, de forma concomitante, nas escolas, isto é, ao mesmo tempo e no mesmo semestre" (DISTRITO FEDERAL, s/d, p. 14). 
No Pará, a organização curricular por blocos de disciplinas foi mencionada como prática inovadora de uma escola em Belém. Segundo relatado, essa escola tinha uma taxa de evasão muito alta, mas contava com um corpo docente bem coeso, que, em sua maioria, permanecia na escola o dia todo. Foi esse grupo de professores que propôs o modelo de grade curricular também por blocos semestrais: no primeiro semestre, o aluno estuda um conjunto de disciplinas e, no segundo, as demais. Muito embora não haja aulas de determinadas disciplinas em um semestre, elas podem ser tratadas por meio de projetos, a depender das necessidades dos jovens. Conforme informado, a comunidade abraçou essa proposta e as taxas de evasão diminuíram.

Já a rede de Santa Catarina experimentou os módulos semestrais e não os aprovou. Os entrevistados afirmaram que a iniciativa fracassou porque tanto alunos como professores não reagiram bem à redução do período a ser avaliado. No processo semestral, os alunos tiveram menos tempo para recuperar notas ruins, gerando reprovação e evasão. Na visão da gerente de ensino médio da rede, "no processo anual, o aluno sabe que, se tiver uma nota ruim, durante o ano ele pode recuperar" e "o professor também tem como trabalhar mais isso: em algum momento, ele vai buscar, ele vai trazendo esse aluno, ele vai conquistando".

No Ceará, há um projeto voltado para "núcleos de interesse". A equipe da Secretaria de Educação, em conjunto com os diretores e professores das escolas, organiza a grade curricular, de forma que todos os alunos do ensino médio sejam liberados das demais aulas em um mesmo momento, para participarem de oficinas: "são experiências por meio das quais os jovens desenvolvem projetos e frequentam oficinas optativas, convivendo com colegas de diferentes turmas e séries do ensino médio, com flexibilidade em termos de horários e temas", explicou o interlocutor entrevistado. Assim, em conjunto com a Secretaria, as escolas alteram a grade curricular e experimentam diferentes modelos de ensino para o ensino médio semestral: as disciplinas não são pensadas para ocorrerem sistematicamente durante toda a semana e, sim, ao longo do semestre, por meio de imersões.

Alguns estados enfrentam enormes problemas de mobilidade e, por isso, encontram dificuldades para chegar a escolas situadas em localidades muito distantes, desenvolvendo para elas algumas estratégias, caso do Pará, Maranhão e Piauí. A rede estadual do Pará conta com o ensino médio modular, seriado. Todos os anos, os alunos estudam quatro módulos de 52 dias de aulas, cada um deles envolvendo um conjunto de disciplinas Os diferentes professores passam 52 dias em cada localidade ensinando um módulo, que corresponde ao conteúdo de sua disciplina para um ano letivo, com quatro avaliações e inclusive recuperações, se elas se fizerem necessárias. 
A rede estadual do Maranhão desenvolve um projeto-piloto a distância para o ensino modular no ensino médio, para locais de difícil acesso. Trata-se do Ensino Médio por Mediação Tecnológica (MTec), que, implantado em 2013, prevê que os alunos sejam organizados por polos localizados em diversos municípios, em 26 salas com professor-tutor. Os componentes curriculares são trabalhados por meio do sistema de TV interativa via satélite, em tempo real. Já o Piauí utiliza o programa Mais Saber, nos mesmos moldes do MTec. Na capital, Teresina, há também algumas escolas que contam com turmas seguindo esse tipo de organização. No entanto, durante a entrevista, apareceram opiniões divergentes, que evidenciaram ser pouco claro, mesmo para a Secretaria de Educação, se o Mais Saber é um programa do ensino médio regular ou se ele atende uma população específica.

O Programa Ensino Médio Inovador (ProEMI), do governo federal, é, ao lado de programas e projetos estaduais próprios, aquele que parece ter, no momento, maior impacto nas escolas de ensino médio. A ampla maioria dos entrevistados indicou o ProEMI como um projeto e/ ou experiência significativa/inovadora em termos do currículo ou grade curricular para esse nível de ensino.

Os depoimentos colhidos indicam que o programa é muito bem-vindo por ter como objetivo a questão curricular-pedagógica, diferentemente de outros cujo foco está na gestão escolar. No Espírito Santo, valorizou-se o ProEMI por ter permitido testar novos currículos via emprego de recursos que chegam diretamente às escolas e favorecem a realização de projetos que integram as disciplinas nas áreas, bem como as áreas entre si, motivando os alunos a se aprofundarem nos conteúdos. De fato, na maioria dos estados investigados, há um número significativo de escolas que aderiu ao programa, com ampliação da carga horária no contraturno. No Distrito Federal, por exemplo, cuja rede de ensino já contava com 3.000 horas obrigatórias, a adesão das escolas ao ProEMI foi total.

Dado que se trata de um programa de redesenho curricular - e como os estados têm empreendido esforços para elaborar e implementar documentos curriculares próprios -, buscou-se entender se e como foi feita a articulação dos PRCs com o documento curricular do próprio estado. Apesar de as secretarias relatarem fazer exatamente isso ao analisar os PRCs, nos depoimentos não apareceu nenhum exemplo concreto que elucidasse essa articulação. Além disso, os entrevistados declararam não dispor de informações detalhadas sobre como tem se dado a efetivação do ProEMI e dificilmente souberam exemplificar propostas inovadoras de alguma escola. Nesse sentido, a maioria afirma ser muito difícil e complexo acompanhar o desenvolvimento dos PRCs, especialmente no que se refere à aplicação de recursos. Mesmo com o apoio dos órgãos regionais, a coordenadora do ensino médio do Distrito 
Federal afirmou, por exemplo, que sente falta de um sistema mais organizado de monitoramento.

Apesar de o ProEMI ter por objetivo induzir mudanças no currículo, seu grande atrativo foi, em alguns estados e em um primeiro momento, justamente a possibilidade de a escola receber recursos diretamente da União, conforme revelam as falas. Em Roraima, onde se teve a oportunidade de visitar duas escolas, coordenadoras e diretoras empenharam-se em mostrar, com entusiasmo, os espaços modificados com os recursos do ProEMI: janelas com tecnologia que impede a invasão da luz solar sem escurecer a sala; bebedouros; novas mesas; casinhas ecológicas; laboratórios de Química, Biologia e Informática. Tem-se a impressão de que, diante da precariedade física desses locais, as questões propriamente curriculares cedem espaço àquelas de infraestrutura, que demandam modificações maiores e mais imediatas.

Ainda em relação aos recursos, foram apontadas dificuldades, em alguns estados, em relação à contrapartida que lhes compete nesse programa. No Pará, por exemplo, quando perguntado sobre como são viabilizadas as ações do ProEMI em relação aos docentes, ou seja, se eles recebem horas adicionais ou se têm tempo reservado na jornada de trabalho para desenvolver os projetos na escola, o entrevistado respondeu negativamente: a rede não conta com condições financeiras para contratar pessoas ou pagar os professores para esse tipo de atividade. Como o ProEMI não permite gastos com pessoal, os docentes acabam participando sem remuneração adicional.

Além das ações que incidem basicamente no percurso escolar do aluno, a maioria dos estados citou também a adesão ao Pacto Nacional pelo Fortalecimento do Ensino Médio, que busca "a articulação e a coordenação de ações e estratégias da União e dos governos estaduais" (BRASIL, 2013, p. 1) em torno das políticas para essa etapa. Em essência, esse programa pretende valorizar os docentes que atuam no ensino médio das redes públicas, disponibilizando formação continuada em cascata: as universidades são responsáveis pela preparação de "formadores estaduais", os quais se encarregarão de capacitar os "orientadores de estudo”, pessoas que irão, finalmente, atuar junto ao professorado do ensino médio, durante as horas previstas na nova jornada de trabalho. Nessa formação, o alvo é analisar o currículo e as práticas pedagógicas adotadas nas escolas, de modo a propiciar a formação humana integral, como apregoam a Lei de Diretrizes e Bases da Educação (LDB) (BRASIL, 1996) e as Diretrizes Curriculares Nacionais para o Ensino Médio (DCNEM) (BRASIL, 2012).

Durante as entrevistas, pode-se dizer, de modo geral, que os depoimentos foram positivos no tocante à relação das secretarias com as universidades e à formação que estas vêm propiciando aos docentes, embora ainda não haja acompanhamento de seus efeitos em sala de 
aula. No Pará, porém, depois de acompanhar uma formação do Pacto feita pela Universidade Federal, o entrevistado ficou com a impressão de que os formadores tratam mais do plano teórico e filosófico e que o cotidiano escolar e sua relação com as políticas do estado não estavam sendo abordados. Já no Maranhão, a entrevistada indicou tentativas de articular a formação realizada pelo Pacto com os documentos curriculares próprios, afirmando que, quando o Pacto surgiu, ela entendia que "não era esse o arcabouço teórico que o professor estava precisando", o que os levou a "uma conversa muito aberta com a universidade, para alinhar o que está previsto no Pacto com o que a rede está precisando”.

Os técnicos do Piauí apontaram um problema de ordem diversa, que afeta a boa realização do Pacto. Segundo eles, embora o recurso para as universidades federais estivesse garantido, faltaram aqueles para levar o pessoal das escolas até os locais de formação, que seria a contrapartida do estado. Tais recursos deveriam vir do Plano de Ações Articuladas (PAR), mas ele estava bloqueado por falta de acompanhamento e atualização das ações do Pacto por parte da própria secretaria. Segundo eles, como o MEC não paga o monitoramento e a maioria dos estados não quer arcar com mais esse custo, eles não recebem os recursos, algo que ocorre também com o ProEMI.

Na fala da interlocutora do MEC, todas as ações para o ensino médio propostas em âmbito nacional - ensino médio integrado à educação profissional, ProEMI, DCNEM/2012, Pacto, Enem - foram pensadas e têm sido implementadas de maneira articulada. A relação dos estados com os programas federais implica maior ou menor dependência, conforme suas peculiaridades e sua configuração política. E, seja em nível nacional seja em estadual, a articulação do currículo com a formação docente e com a avaliação é um desafio bastante complexo, o qual os gestores das políticas educacionais precisam enfrentar.

\section{CONSIDERAÇÕES FINAIS}

Flexibilização, opções para os alunos, diversidade no conteúdo do ensino médio, possibilidade de aprofundar-se em disciplinas com as quais se tem maior afinidade, escola de ensino integral e diferentes tipos de ensino profissional, aspectos presentes em nossa legislação desde a LDB, que ganharam força com as DCNEM 2012 e são recorrentemente apontados como alternativas para atrair e manter os jovens no ensino médio. Também são esses os pontos levantados como centrais para a reforma do EM, prevista na Lei n. 13.415, implementada como medida provisória ao final de 2016 e sancionada em fevereiro de 2017. Dentre os muitos aspectos nela enfocados, estão os itinerários flexíveis, os quais deverão ser escolhidos pelos alunos entre cinco áreas do conhecimento: linguagem e suas tecnologias, matemática e suas tecnologias, ciências da natureza 
e suas tecnologias, ciências humanas e sociais aplicadas ou formação técnica profissional.

Os dados desta pesquisa indicam que, se esses aspectos não foram implementados adequadamente até o momento, foi por falta de infraestrutura, recursos e incentivos federais e estaduais. A parte comum, prevista na LDB, é o espaço para a Base Nacional Comum Curricular, que está em elaboração; a parte diversificada deveria contemplar tópicos eletivos do currículo, espaço para escolhas dos alunos, podendo envolver conteúdos típicos do ensino médio ou outros que revelam ampliação de repertório em diferentes áreas de interesses dos jovens. Porém, apesar de se falar muito que as escolas devem inovar, diversificar, etc., não são oferecidas condições para que isso ocorra. Na verdade, as próprias secretarias de educação colocam entraves econômicos e institucionais, de tempo e de espaço, que limitam as chances de elas mesmas inspirarem modelos inovadores. Nesse sentido, pouca orientação é dada às escolas a respeito de como definir e trabalhar os conteúdos da parte diversificada, de maneira a oferecer possibilidades formativas com diferentes itinerários.

Acrescenta-se que a falta de infraestrutura e de recursos pode afetar também a implementação da reforma do EM a ser realizada. A mudança de legislação que prevê diferentes itinerários formativos não garante que as escolhas dos alunos sejam diversificadas e interessantes para todos eles. Se o Estado não tiver condições de implementar a infraestrutura necessária para essa reforma em todas as escolas, corre-se o risco de diminuir a escolha dos alunos - já que nem todos os percursos serão ofertados - e aumentar as desigualdades de oportunidades, criando diferentes categorias de escola.

Vale ressaltar que a questão da desigualdade se repete em outros achados da pesquisa. Constatou-se que os dez estados pesquisados oferecem diferentes modalidades de ensino médio, já que ofertam o regular, o técnico integrado à educação profissional, o técnico concomitante e o subsequente. Essa flexibilização na oferta de modelos suscita duas possíveis reflexões: não temos, no país, apenas um modelo único de ensino médio, o que, como concepção, é interessante, pois permite atender a diferentes demandas e necessidades das diversas juventudes. Por outro lado, essa gama de oferta não se dá de maneira equânime e nem com a mesma qualidade para os alunos que estão na faixa etária correspondente: nem todos que querem acessar uma dessas opções terão oportunidade de fazê-lo. De fato, a educação profissional ainda não alcança grandes parcelas de alunos de ensino médio e em nenhum dos estados pesquisados verificou-se uma preocupação em priorizar um público específico, como os mais vulneráveis socioeconomicamente, por exemplo. Desse modo, dependendo da forma como é implementada, a diversificação da oferta pode suscitar maior desigualdade educacional e social.

Nesse sentido, é claro que as escolas em tempo integral têm mais espaço para promover projetos inovadores e diversificados, mas nem 
mesmo nesses casos foram mencionados exemplos de práticas exitosas. Quando se volta para o ensino médio noturno, tanto na parte comum do currículo quanto na diversificada, as limitações são ainda maiores. Apesar de atender a mais de 30\% dos alunos do ensino médio em vários estados, não foi encontrada nenhuma iniciativa específica voltada para esse grupo que, mais desfavorecido socioeconomicamente, enfrenta maiores dificuldades para frequentar a escola e acaba não sendo contemplado pelas principais políticas destacadas pelos estados.

Por outro lado, nota-se a ênfase das secretarias estaduais de educação em valorizar o acesso ao ensino superior, até porque entendem que essa é atualmente a principal demanda e expectativa dos jovens. Em todos os estados, existe a oferta de cursinhos preparatórios para o vestibular, que são meios mais baratos de atender a essa necessidade. No mesmo sentido, a escolha curricular baseada nos programas do Enem e dos principais vestibulares regionais é comumente observada. Mesmo assim, nem todos os alunos parecem se interessar ou se considerar capazes de prestar vestibular, tendo em vista as taxas de participação no Enem apresentadas. Esses dados parecem indicar que nem mesmo aquilo que está sendo priorizado nos estados traz necessariamente aumento das expectativas dos jovens estudantes no que se refere à escolha de sua futura profissão.

Para finalizar, é preciso destacar que os programas oferecidos pelos estados para atrair e manter os jovens na instituição escolar de ensino médio estão no nível do sistema de ensino e não das escolas. Ou seja, eles têm um limite para impactar essa relação, pois muitas vezes são as características internas de cada escola que podem favorecer - ou não - a permanência dos alunos. O olhar e a postura dos educadores, suas expectativas em relação à aprendizagem dos alunos, a relação entre as gerações e o clima escolar são algumas dessas características que, apesar de muito difíceis de serem captadas e lentas para serem transformadas, devem merecer também atenção das políticas públicas.

\section{REFERÊNCIAS}

ABRAMO, Helena; BRANCO, Pedro Paulo M. (Org.). Retratos da juventude brasileira: análises de uma pesquisa nacional. São Paulo: Instituto da Cidadania; Fundação Perseu Abramo, 2005.

ABRAMOVAY, Mirian (Coord.). Juventudes na escola, sentidos e buscas: por que frequentam? Brasília-DF: Flacso - Brasil, OEI, MEC, 2015.

BRASIL. Lei no 9.394, de 20 de dezembro de 1996. Lei de Diretrizes e Bases da Educação Nacional. Brasília: Casa Civil, MEC, 1996. Disponível em: <http://portal.mec.gov.br/arquivos/pdf/ldb.pdf>. Acesso em: 14 maio 2014.

BRASIL. Emenda Constitucional no 59, de 11 de novembro de 2009. Brasília: Casa Civil, 2009a. Disponível em: <http://www.planalto.gov.br/ccivil_03/constituicao/Emendas/Emc/emc59.htm>. Acesso em: 14 maio 2014.

BRASIL. Ministério da Educação. Diretoria de Concepções e Orientações Curriculares para a Educação Básica. Coordenação Geral de Ensino Médio. Programa Ensino Médio Inovador: documento orientador. Brasília: MEC/COCEM/CGEM, 2009b. 
BRASIL. Ministério da Educação. Conselho Nacional de Educação. Câmara de Educação Básica. Parecer CNE $n^{\circ}$ 5, de 04 de maio de 2011. Brasília: MEC/CNE/CEB, 2011. Disponível em: <http:// portal.mec.gov.br/index.php?option=com_content\&id=16368\&Itemid=866>. Acesso em: 15 maio 2014.

BRASIL. Ministério da Educação. Conselho Nacional de Educação. Câmara de Educação Básica. Resolução $n^{o}:$ 2, de 30 de janeiro de 2012. Define Diretrizes Curriculares Nacionais para o Ensino Médio. Brasília: MEC/CNE/CEB, 2012. Disponível em: < http://pactoensinomedio.mec.gov.br/ images/pdf/resolucao_ceb_002_30012012.pdf>. Acesso em: 8 maio 2014.

BRASIL. Ministério da Educação. Secretaria de Educação Básica. Pacto Nacional pelo Fortalecimento do Ensino Médio. Brasília: MEC/SEB, 2013. Disponível em: <http://pactoensinomedio.mec.gov.br/ images/pdf/pacto_fort_ensino_medio.pdf>. Acesso em: 15 maio 2014.

BRASIL. Lei ñ 13.005, de 25 de junho de 2014. Aprova o Plano Nacional de Educação - PNE e dá outras providencias. Brasília: Casa Civil, 2014. Disponível em: <http://www.planalto.gov.br/ ccivil_03/_Ato2011-2014/2014/Lei/L13005.htm>. Acesso em: 20 fev. 2015.

BRASIL. Instituto Nacional de Estudos e Pesquisas Educacionais Anísio Teixeira - Inep. Censo escolar da educação básica - 2014. Brasília: Inep, 2015.

BRASIL. Instituto Nacional de Estudos e Pesquisas Educacionais Anísio Teixeira - Inep. Censo escolar da educação básica - 2015. Brasília: Inep, 2016.

CENTRO DE ESTUDOS E PESQUISAS EM EDUCAÇÃO, CULTURA E AÇÃO COMUNITÁRIA CENPEC; INSTITUTO DE ASSESSORIA E PESQUISA EM LINGUAGEM - LITTERIS. O jovem, a escola e o saber: uma preocupação social no Brasil. In: CHARLOT, Bernard (Org.). Os jovens e o saber: perspectivas mundiais. Porto Alegre: Artmed, 2001. p. 34-50.

CORTI, Ana Paula. Ensino médio em São Paulo: a expansão das matrículas nos ano 1990. Educação e Realidade, Porto Alegre, v. 41, n. 1, p. 41-68, jan./mar. 2016.

DAVIS, Claudia; TARTUCE, Gisela Lobo B. P.; ALMEIDA, Patrícia C.; NUNES, Marina M. R. SILVA, Ana P. F. da; SOUZA, Juliana C. de; COSTA, Beatriz Souza D. de Olival. Anos finais do ensino fundamental: aproximando-se da configuração atual: relatório final. São Paulo: Fundação Victor Civita, 2012. Disponível em: <http://www.fvc.org.br/pdf/desafios-dos-anos-finais-ensinofundamental-alta-relatorio-final.pdf>. Acesso em: 10 fev. 2015.

DAYRELL, Juarez. Juventude e escola. In: SPOSITO, Marilia P. (Coord.). Juventude e escolarização (1980-1998). Brasília: MEC/Inep/Comped, 2002. p. 39-78. (Estado do Conhecimento, 7)

DAYRELL, Juarez; NONATO, Bréscia F.; DIAS, Fernanda V.; DO CARMO, Helen C. Juventude e escola. In: SPOSITO, Marilia P. (Coord.). Estado da arte sobre juventude na pós-graduação brasileira: educação, ciências sociais e serviço social (1999-2006). Belo Horizonte: Argvmentvm, 2009. p. 57-126.

DAYRELL, Juarez; GOMES, Nilma Lino; LEÃO, Geraldo. Escola e participação juvenil: é possível esse diálogo? Educar em Revista, Curitiba, n. 38, p. 237-252, set./dez. 2010.

DISTRITO FEDERAL (Estado). Secretaria de Educação. Currículo em movimento da educação básica: ensino médio. Brasília: SEE, s/d. 84p.

FILARDO, Veronica. Integralidad em el análisis de trajectorias educativas. Educação e Realidade, v. 41 , n. 1, p. 15-40, jan./mar. 2016.

INSTITUTO BRASILEIRO DE GEOGRAFIA E ESTATÍSTICA - IBGE. Pesquisa nacional por amostra de domicílios - PNAD 2014. Rio de Janeiro: IBGE, 2015.

KLEIN, Ana Maria; ARANTES, Valéria A. Projetos de vida de jovens estudantes do ensino médio e a escola. Educação e Realidade, Porto Alegre, v. 41, n. 1, p. 135-154, jan./mar. 2016.

LARANJEIRA, Denise H. P.; IRIART, Mirela F. S.; RODRIGUES, Milena S. Problematizando as transições juvenis na saída do ensino médio. Educação e Realidade, Porto Alegre, v. 41, n. 1, p. 117-134, jan./mar. 2016.

MADEIRA, Felicia. Os jovens e as mudanças estruturais na década de 70: questionado pressupostos e sugerindo pistas. Cadernos de Pesquisa, São Paulo, n. 58, p. 15-48, ago. 1986. 
MANSUTTI, Maria Amabile. Tempos e espaços na escola. In: BRASIL. Ministério da Educação. Secretaria de Educação Básica. Caderno de reflexões: jovens de 15 a 17 anos no ensino fundamental. Brasília: Via Comunicação, 2011. p. 65-74.

MESQUITA, Silvana S.de A. O exercício da docência no ensino médio: a centralidade do papel do professor no trabalho com jovens da periferia. 2016. Tese (Doutorado em Educação) - Pontifícia Universidade Católica do Rio de Janeiro, Rio de Janeiro, 2016.

MARANHÃO. Secretaria de Educação. Diretrizes curriculares. 3. ed. São Luís: Seduc, 2014. 107p.

ORGANISATION FOR ECONOMIC CO-OPERATION AND DEVELOPMENT. Education at a glance 2014: OECD indicators. Paris: OECD, 2014.

PARÁ. Secretaria de Educação. Proposta curricular: ensino médio. Belém: SEE, 2003. 137p.

PEREIRA, Beatriz P.; LOPES, Roseli Esquerdo. Por que ir à escola? Os sentidos atribuídos pelos jovens do ensino médio. Educação e Realidade, Porto Alegre, v. 41, n. 1, p. 193-216, jan./mar. 2016.

SALES, Celecina V.; VASCONCELOS, M. Aurilene D. M. Ensino médio integrado e juventudes: desafios e projetos de futuro. Educação e Realidade, Porto Alegre, v. 41, n. 1, p. 69-90, jan./mar. 2016.

SILVA, Teresa R. Neubauer da; DAVIS, Claudia Leme F.; NUNES, Marina Muniz R.; TARTUCE, Gisela Lobo B. P. Melhores práticas em escolas do ensino médio - estados envolvidos: Acre, Ceará, Paraná e São Paulo: relatório final. São Paulo: Fundação Carlos Chagas; Instituto de Protagonismo Jovem e Educação; BID, 2009.

SIMÕES, Armando. Acesso e evasão na educação básica: as perspectivas da população de baixa renda no Brasil. Brasília: MDS, 2014. (Estudos Técnicos SAGI, n. 4).

SPOSITO, Marilia P. (Coord.). Juventude e escolarização (1980-1998). Brasília: MEC/Inep/Comped, 2002. (Estado do Conhecimento, 7)

SPOSITO, Marilia P. Uma perspectiva não escolar no estudo sociológico da escola. Revista USP, São Paulo, n. 57, p. 210-226, mar./maio 2003.

SPOSITO, Marilia P. Algumas reflexões e muitas indagações sobre as relações entre juventude e escola no Brasil. In: ABRAMO, Helena; BRANCO, Pedro Paulo M. (Org.). Retratos da juventude brasileira: análises de uma pesquisa nacional. São Paulo: Instituto da Cidadania; Fundação Perseu Abramo, 2005. p. 87-127.

SPOSITO, Marilia P. Juventude: crise, identidade e escola. In: DAYRELL, Juarez (Org.). Múltiplos olhares sobre a educação e cultura. Belo Horizonte: UFMG, 2006. p. 96-104.

SPOSITO, Marilia P. (Coord.). Estado da arte sobre juventude na pós-graduação brasileira: educação, ciências sociais e serviço social (1999-2006). Belo Horizonte: Argvmentvm, 2009. v. 2, 276 p. (Edvcere; 10)

TARTUCE, Gisela Lobo B. P. Jovens na transição escola-trabalho: tensões e intenções. São Paulo: Annablume; Fapesp, 2010. (Trabalho \& Contemporaneidade)

TARTUCE, Gisela Lobo B. P.; DAVIS, Claudia Leme F.; MORICONI, Gabriela; NUNES, Marina Muniz R.; CHRISTOV, Luiza H. S. Ensino médio: políticas curriculares dos estados brasileiros: relatório final. São Paulo: Fundação Victor Civita, 2015. Disponível em: <http://fvc.org.br/pdf/ FCC_Relatorio_Final_F.pdf>. Acesso em: 21 fev. 2017.

TORRES, Haroldo da G.; FRANÇA, Danilo; TEIXEIRA, Jacqueline; CAMELO, Rafael; FUSARO, Edgard. O que pensam os jovens de baixa renda sobre a escola: relatório final. São Paulo: Fundação Victor Civita, 2013. Disponível em: <www.fvc.org.br/estudos>. Acesso em: 10 fev. 2015.

UNITED NATIONS CHILDREN'S FUND; VOLPI, Mário; SILVA, Maria de Salete; RIBEIRO, Júlia (Coord.). 10 desafios do ensino médio no Brasil: para garantir o direito de aprender de adolescentes de 15 a 17 anos. Brasília: Unicef, 2014.

ZIBAS, Dagmar; FERRETTI, Celso J.; TARTUCE, Gisela Lobo B. P. A gestão escolar como cenário de inovação educativa: o protagonismo de alunos e pais no ensino médio; cinco estudos de caso: relatório final. São Paulo: Fundação Carlos Chagas; OEI, 2004.

Recebido em: 14 AGOSTO 2017 | Aprovado para publicação em: 28 NOVEMBRO 2017 